\title{
A dimensão ética da formação profissional em saúde: estudo de caso com cursos de graduação em odontologia
}

\author{
The ethical dimension of professional training in health: \\ a case study in undergraduate dentistry courses
}

\author{
Mirelle Finkler ${ }^{1}$ \\ João Carlos Caetano ${ }^{1}$ \\ Flávia Regina Souza Ramos ${ }^{1}$
}

${ }^{1}$ Universidade Federal de Santa Catarina. Campus Universitário Reitor João David Ferreira Lima, Trindade. 88040-970 Florianópolis SC. mirellefinkler@yahoo.com.br

\begin{abstract}
This case study sought to delineate an overview of ethics training on Brazilian undergraduate dentistry courses, in order to gather knowledge related to the changes required with regard to training ethically competent health professionals. Thus, the scope of this study-ethics training of students - was defined by a conceptual reference, constructed at the interface of interrelated concepts. The reference also contributed to the outlining of this qualitative research, which includes a questionnaire with ethical-pedagogical questions, sent to the coordinators of 15 courses selected for the sample. The results indicated a timely commitment of the courses to the ethical dimension of professional training, as well as advances in training of teaching staff, the profile of the graduate and the curricular integration process. On the other hand, they highlighted deficiencies regarding the contents concerned with the cultural, humanistic and political background in relation to didactic orientation, the teachinglearning scenarios, the evaluation process, and also the incipient presence of bioethics regarding the subject and the crossover curricular theme, together with the lack of specific training of the teaching staff.
\end{abstract}

Key words Ethics, Bioethics, Higher Education, Human Resources in Dentistry, Education in Dentistry, Dentistry Schools
Resumo Trata-se de um estudo de caso que objetivou delinear um panorama da formação ética nos cursos de graduação em Odontologia brasileiros, a fim de construir conhecimentos relativos às mudanças necessárias no sentido de se formar profissionais de saúde eticamente competentes. Para tanto, o objeto deste estudo - a formação ética dos estudantes - foi delimitado por um marco conceitual, construído na interface de diversos conceitos inter-relacionados. O marco também colaborou no delineamento desta pesquisa qualitativa, que incluiu um questionário com questões ético-pedagógicas, enviado aos coordenadores dos 15 cursos selecionados para amostra. Os resultados apontaram um comprometimento pontual dos cursos com a dimensão ética da formação profissional, bem como avanços em relação à capacitação docente, ao perfil do egresso e ao processo de integração curricular. Por outro lado, indicou deficiências quanto aos conteúdos relacionados à formação cultural, humanística e política, em relação à orientação didática e aos cenários de ensino-aprendizagem, ao processo avaliativo, além da incipiente presença da Bioética enquanto disciplina e tema transversal curricular, acompanhada pela escassa formação específica de seus docentes.

Palavras-Chave Ética, Bioética, Educação Superior, Recursos Humanos em Odontologia, Educação em Odontologia, Escolas de Odontologia 


\section{Introdução}

As inquietudes e necessidades atualmente vividas pelas diversas profissões quando da formulação do perfil do seu egresso universitário mostram a imperiosa necessidade da instituição universitária entender que formação ética não diz respeito a boas intenções, mas à efetividade e à excelência na formação profissional (FP). Conceitos como cidadania, ética, moral e valores devem ser centrais neste processo, porque as sociedades atuais necessitam, mais do que nunca, de cidadãos éticos, que atuem de forma prudente, responsável e comprometida, capazes de vivenciar e de promover a realização dos valores humanizadores ${ }^{1,2}$.

$\mathrm{Na}$ área da saúde, a competência ética dos futuros profissionais é entendida como a capacidade autônoma de percepção, reflexão crítica e decisão coerente em relação às condutas humanas no cuidado à saúde e à vida. O desenvolvimento desta competência requer docentes capacitados e dispostos a assumir a discussão de aspectos relativos à prática educativa, de modo a favorecer uma formação mais centrada no educando e mais qualificada para a sociedade que subsidia e depende desta formação ${ }^{3}$. Isto exige que os próprios docentes desenvolvam competências como a crítica e a reflexão. Mas o ensino tradicional de Odontologia - fragmentado, desarticulado, tecnicista, positivista, baseado na pressuposta neutralidade científica - ainda constitui a matriz curricular na formação de seus docentes ${ }^{4,5}$. Embora o progresso técnico-científico na área tenham sido extraordinário nas últimas décadas, o mesmo não ocorreu com seu embasamento ético, tão necessário a boa prática profissional.

Além disso, a pós-graduação e a produção científica são fortemente influenciadas pelos critérios de avaliação da Coordenação de Aperfeiçoamento de Pessoal de Nível Superior (CAPES) do Ministério de Educação, que seguem o modelo da sociedade neoliberal vigente, sob a lógica do mercado (modelo de avaliação produtivista, baseado na eficiência, no número de publicações e nos interesses próprios do mercado ${ }^{6}$, resultando em uma formação pouco crítico-reflexiva e em uma produção científica ética e socialmente descomprometida ${ }^{7}$.

O professor representa um modelo a ser seguido pelos estudantes, tanto em relação às suas habilidades técnicas, quanto à sua postura ética diante das situações cotidianas no atendimento a pacientes. Ao observar o professor, o estudante tende a assimilar sua conduta. É sua tarefa, portanto, suscitar a reflexão ética sobre as questões vivenciadas e fornecer/compartilhar as informações necessárias para subsidiar tal exercício de reflexão ${ }^{8}$. É sua tarefa contribuir positiva e intencionalmente na formação ética dos estudantes.

Por formação ética, ou melhor, pela dimensão ética da FP entende-se o ensino/ aprendizagem/ vivência da ética em bases não deontológicas, compromissado com o desenvolvimento e a realização de valores humanizadores e com a conformação da identidade profissional durante a graduação. Ou seja, envolve tudo aquilo que contribui para que o profissional pense, aja e reaja às situações profissionais de determinada forma ou com determinado padrão de atitudes ${ }^{9}$.

A dimensão ética da FP é composta por uma série de fatores que vão desde influências do processo de socialização primária, que se inicia precocemente na infância ${ }^{10}$, até as questões diretamente relacionadas ao desenvolvimento moral $^{1,11,12}$ que acontece durante a graduação, passando pelo mundo da profissão e do trabalho em saúde ${ }^{13}$, pelas particularidades da $\mathrm{FP}^{14,15}$, pelo processo de socialização profissional ${ }^{10,16,17}$ e pelo currículo formal e oculto ${ }^{18}$. Na interface destes conceitos o objeto de pesquisa pôde ser delimitado em um marco conceitual, direcionando a busca de estratégias metodológicas que possibilitassem alcançar o objetivo desta pesquisa de compreender como vem sendo desenvolvida a dimensão ética dos estudantes de Odontologia no Brasil.

\section{Metodologia}

Quando em um contexto de vida real se busca apreender um fenômeno na sua totalidade, descrevendo, compreendendo e interpretando a complexidade de um caso concreto, a partir de uma variedade de evidências, caracteriza-se a pesquisa como sendo um estudo de caso $^{19}$. De fato, este estudo descritivo pode assim ser definido, pois investiga um fenômeno contemporâneo sobre o qual não se possui controle, qual seja a formação ética nas escolas de Odontologia brasileiras (e não o estudo dos diferentes cursos que participaram como fontes de evidências). Empregou-se a abordagem qualitativa por ser considerada a mais adequada à compreensão de fenômenos específicos e delimitáveis, mais pelo seu grau de complexidade interna do que por sua expressão quantitativa. Tal definição não se trata de uma escolha metodológica entre o método quantitativo e o qualitativo, pois, a rigor, a escolha real é a do objetivo de pesquisa que surge de uma hipótese de trabalho ou dos pressupostos do pesquisador ${ }^{20}$. 
Os cursos participantes foram selecionados de modo a compor uma amostra da sua distribuição nacional, em termos de proporção entre cursos públicos e privados, e de localização, por regiões geográficas. Desta forma, das 17 escolas $( \pm 10 \%$ do total $)$ convidadas a participar do estudo, 15 concordaram, compondo uma amostra com 5 cursos públicos $(33 \%)$ e 10 privados (66\%). Quanto à localização, 10 (66\% do total) foram selecionadas nas regiões sul e sudeste, e 5 (33\%), dentre as demais regiões. A coleta de dados foi iniciada após a aprovação ética do projeto de pesquisa e dos Termos de Consentimento Livre e Esclarecidos pelo Comitê de Ética em Pesquisa da Universidade de Santa Catarina.

$\mathrm{Na}$ primeira etapa, um questionário (baseado no modelo do construído por Lampert ${ }^{12}$ ) foi elaborado a partir dos fatores relacionados ao currículo formal que influenciam a dimensão ética da FP. As questões contemplaram três categorias temáticas: enfoque teórico, abordagem pedagógica e abordagem ética. $\mathrm{O}$ instrumento foi avaliado por especialistas e pré-testado, sendo então enviado aos coordenadores de cada curso. Cada uma das 14 questões (unidades temáticas) possuía 3 possíveis afirmações (e um espaço aberto para o relato de justificativas e evidências), dentre as quais os coordenadores deveriam eleger a que mais se assemelhava a experiência predominantemente vivenciada no curso. Estas afirmações foram elaboradas pensando-se em situações distintas que caracterizariam o processo de mudanças curriculares em cada escola, por sua vez, paralelas ao modelo de ensino e ao nível de comprometimento com a formação ética dos estudantes. Assim, as respostas A contemplavam o modelo mais tradicional e hegemônico de ensino em saúde, nos moldes flexnerianos, com um enfoque teórico biomédico predominante, com uma estrutura curricular segmentada, e o ensinoaprendizagem centrado no professor com ênfase em aulas teóricas expositivas e práticas demonstrativas etc. A este modelo de ensino correlacionou-se um comprometimento com a formação ética denominado de "inexpressivo", que seria aquele em que a ética é conceituada como Deontologia, havendo um corpo docente que não se julga responsável pela formação ética dos estudantes. As respostas B caracterizavam um modelo inovador, havendo um equilíbrio do enfoque biológico e do social, com alguma integração curricular e multidisciplinar, embora ainda com ênfase em aulas teóricas centradas nos docentes. A este modelo corresponderiam os cursos de comprometimento "pontual" com a formação ética, ou seja, aqueles que introduzem a temática da Bioética, abordando questões éticas de forma isolada, com apenas alguns docentes ou disciplinas comprometidos. Já as respostas $\mathrm{C}$ delineavam um modelo mais avançado no sentido do paradigma da integralidade, tomando por base um enfoque teórico epidemiológico-social, com o currículo estruturado em módulos, com o emprego de metodologias ativas, enfatizando a realidade de saúde com abordagem multidisciplinar em serviços e espaços comunitários nas práticas. A este modelo correlacionou-se um comprometimento "abrangente", no qual a formação ética é entendida como uma das dimensões da FP, devendo ser inserida transversalmente no currículo e sendo valorizada por grande parte do corpo docente que atua consciente e intencionalmente no desenvolvimento moral dos estudantes. Vale ainda dizer que, embora o questionário não esteja presente neste texto, pode-se acessá-lo on-line ${ }^{21}$.

A partir destes resultados, as demais etapas da pesquisa buscaram apreender os fatores do currículo oculto que influenciam a dimensão ética FP. Por meio de análise documental, entrevistas semidirigidas, grupos focais e observações, o aprofundamento da pesquisa foi realizado em duas instituições. Contudo, neste texto se analisam apenas os primeiros resultados desta pesquisa $^{21}$, os quais já possibilitaram a construção de um panorama sobre a atual situação da formação ética profissional em Odontologia.

Dos 15 questionários devolvidos, 5 apresentavam algumas questões não assinaladas (às vezes com apenas alguma justificativa registrada) e/ ou outras questões com duas alternativas eleitas. Nestes casos, buscou-se identificar a alternativa mais apropriada de acordo com o contexto apresentado na justificativa da questão, bem como no restante do questionário, pois a tabulação dos resultados não permitia a possibilidade de manter questões sem resposta ou com dupla resposta. Quando a identificação da alternativa mais adequada não foi possível, manteve-se a alternativa assinalada mais abrangente em relação ao comprometimento com a formação ética.

A figura que ilustra os resultados seguiu o modelo radiado proposto por Lampert ${ }^{14}$ (Figura 1) "que simula uma expansão, um voltar-se de dentro para fora da instituição, para interagir no contexto, à medida que avance nas reformas curriculares", neste caso, em direção a um comprometimento mais abrangente com a dimensão ética da FP.

O modelo é composto por três círculos, representativos dos diferentes níveis do compro- 


\section{ENFOQUE TEÓRICO}

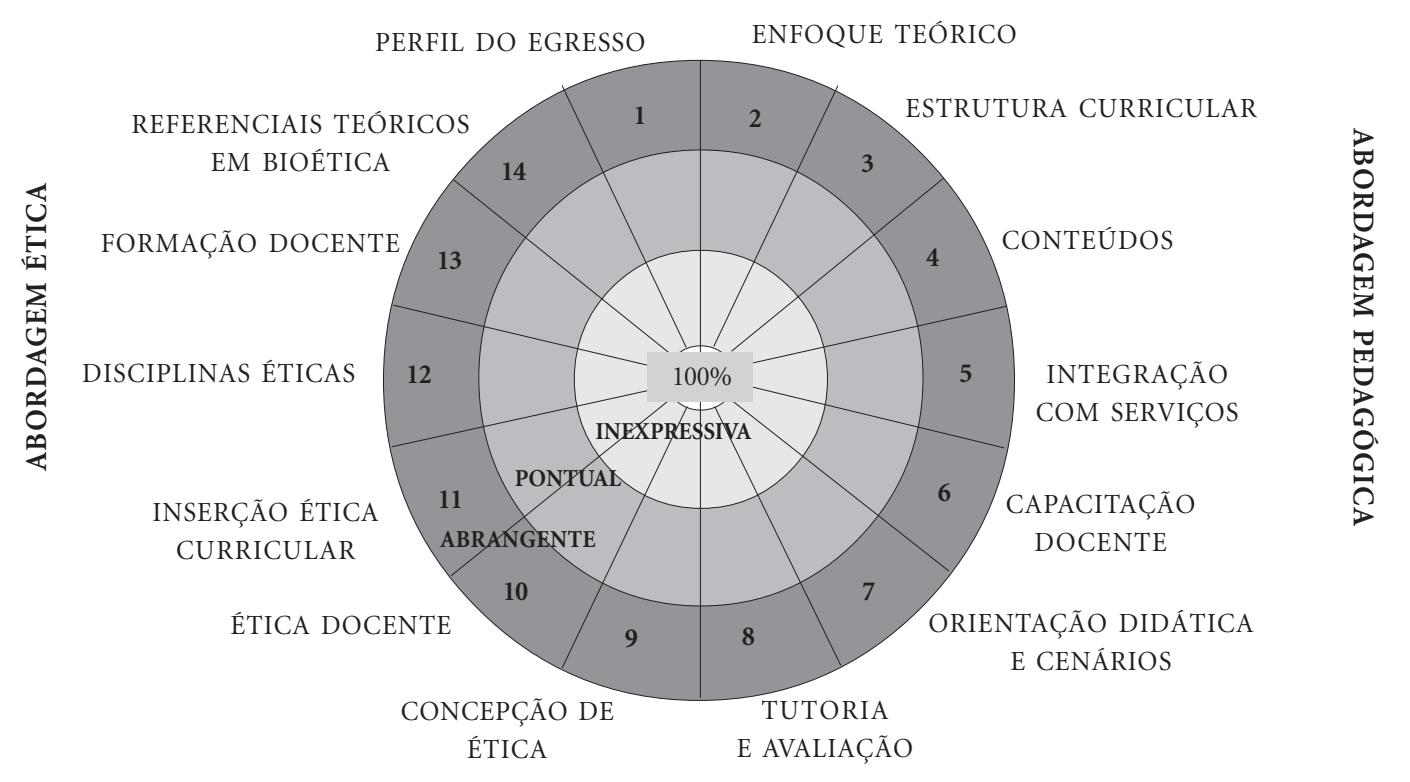

Figura 1. Modelo radiado, com as três categorias e respectivas unidades temáticas relevantes à formação ética, além dos três círculos relativos aos diferentes níveis de comprometimento com esta dimensão da formação profissional, usada na representação das respostas dos questionários aplicados nas 15 faculdades participantes.

metimento das faculdades com a FP ética ("inexpressiva" - nível interno, "pontual" - nível intermédio e "abrangente" - nível externo), em cada uma das três categorias e respectivas unidades temáticas. No centro da figura, apresenta-se o percentual total da área expandida. Deste modo, à medida que as faculdades relatavam estar em posições mais avançadas, uma maior área do círculo era coberta, sendo quantificada em valores porcentuais. A fim de operacionalizar esta categorização, tendo em vista posições intermediárias, e de classificá-la, adotou-se as seguintes padronizações: de $33.33 \%$ a 49,98\% - comprometimento inexpressivo; de $49,99 \%$ a $66,65 \%$ - comprometimento pontual com tendência à inexpressivo (pontual I); de $66,66 \%$ a $83,31 \%$ - comprometimento pontual com tendência à abrangente (pontual A); e de 83,32\% a 99,99\% - comprometimento abrangente.

\section{Resultados e discussão}

Na Tabela 1 os resultados são classificados de acordo com o comprometimento predominante do conjunto de faculdades em relação à dimensão ética da FP. Como se pode observar na tabela, apenas dois coordenadores consideram que o perfil dos egressos de seus cursos ainda é o tradicional (formação para um mercado de trabalho basicamente liberal, com alta valorização da clínica). Possivelmente, as mudanças recentes no trabalho em saúde (implementação das equipes de saúde bucal na Estratégia de Saúde da Família e dos Centros de Especialidades Odontológicas) contribuem para que os cursos atualmente se preocupem em preparar cirurgiões-dentistas com um perfil generalista, capazes, pelo menos razoavelmente, de trabalhar no SUS, quando não bastante familiarizados com seus serviços e com as demandas da sociedade. Contudo, os sete coordenadores que elegeram a resposta mais abrangente nesta unidade temática, não fizeram referências às qualidades citadas no enunciado da alternativa - "perfil autônomo, crítico e reflexivo", no máximo comentando o perfil humanista desejado e ainda assim, com poucas evidências. Deste modo, algumas das características importantes para o exercício da profissão em um nível de excelência, que é a obrigação moral de todo 
profissional, parecem não ser suficientemente valorizadas e desenvolvidas.

As faculdades predominantemente ministram o curso buscando um equilíbrio no enfoque biológico e social (onze), sendo poucas as que relataram tomar como base o enfoque epidemiológico com ênfase na determinação social do processo saúde-doença (quatro). Deste modo, observa-se o indício positivo de que nenhum curso segue tomando como enfoque teórico apenas as questões biomédico-clínicas, ao que corresponderia um perfil de egresso tradicional. Contudo, observou-se nas evidências uma atribuição de responsabilidade quase exclusiva às disciplinas de Saúde Coletiva pela "porção" ou concepção social deste enfoque teórico. É inegável sua contribuição neste sentido, mas questionável a manutenção ainda hoje das demais disciplinas na visão biologicista. Também se observou que a quantidade de respostas mais abrangentes em perfil do egresso não foi amparada pelas respostas correspondentes em enfoque teórico. Ou seja, não houve uma coerência esperada entre os cursos que relataram o alcançar o perfil profissional preconizado pelas Diretrizes Curriculares Nacionais (DCN) (sete) e os que afirmaram trabalhar sob o enfoque epidemiológico (quatro). Em vista disto, aventa-se uma tangibilidade maior nesta unidade temática que em perfil do egresso. Significa dizer que talvez a maior facilidade em "visualizar" o enfoque teórico do curso (por exemplo, pelas disciplinas da grade curricular - algo concreto e mais facilmente verificável) que a atuação do egresso (menos conhecida e/ou avaliada), influencie de modo importante as respostas selecionadas, no sentido de refletirem mais ou menos a realidade efetivamente vivenciada.

As faculdades relatam o predomínio da integração parcial do currículo com a manutenção da organização em ciclo básico e profissionalizante (oito). Contudo, apenas três delas forneceram evidências efetivas disto, distinguindo-se de outras que podem ter considerado o currículo parcialmente integrado pela simples existência de clínicas integradas ao final do curso. É importante também perceber o número significativo de cursos que já trabalham com o currículo em grande parte integrado (seis), desenvolvendo conteúdos profissionalizantes desde o início, com a inserção do estudante na clínica e/ou no SUS desde o primeiro ano do curso.

A opção de diversas faculdades (onze) pela alternativa "b) esta escola predominantemente valoriza a formação humanística, cultural e política dos estudantes e oferece disciplinas que trabalham/desenvolvem conteúdos relacionados" parece não estar plenamente justificada quando a fazem afirmando a existência de uma única disciplina de humanidades que promove a aproximação dos alunos com as diferentes realidades 
sociais. Possivelmente, a alternativa “a) não enfatiza conteúdos relacionados à formação humanística, cultural e política dos estudantes" haveria sido mais apropriada em alguns destes casos. Nenhuma faculdade, no entanto, elegeu esta alternativa. Provavelmente a diferença entre o "não enfatiza" da primeira alternativa e o "valoriza" da segunda não foi adequadamente compreendida. Uma postura mais avançada foi mostrada por apenas quatro faculdades que relataram, ademais de valorizar e ofertar tal formação aos estudantes, promover oportunidades de aprimoramento nestas temáticas à grande parte dos docentes. Contudo, as evidências apontadas estiveram basicamente restritas à oferta de disciplinas ou à capacitação docente, extrapolando apenas em três casos que citaram a vivência no setor público/ comunidade como importante para a formação citada, e um quarto que relatou tomar decisões colegiadas em todos os níveis. Assim, a participação ativa dos estudantes em questões políticas - como poderia acontecer em centros acadêmicos, na representação discente universitária, ou em questões humanísticas e culturais, como o engajamento em eventos solidários ou em entidades comunitárias foi pouquíssimo evidenciado, coerentemente com o percebido e já comentado em perfil do egresso.

A integração com os serviços de saúde foi a unidade temática que mais apresentou inconsistências (quatro) entre as respostas eleitas e as justificativas e evidências registradas. Assim, embora a tabulação dos dados aponte um maior número de faculdades (oito) classificadas como de comprometimento abrangente em relação a este tema, estando as demais como pontuais (seis) e apenas uma como inexpressivo, uma reclassificação das respostas a partir das informações contidas nos questionários, levaria a uma divisão equitativa das respostas dadas às três afirmativas fornecidas, pelo qual os resultados acima devem ser considerados com precaução. As justificativas e evidências aportadas foram as mais variadas, mas as inconsistências assinaladas se devem, basicamente, ao conceito de serviços docente-assistenciais, que parece não ter sido sempre considerado. De fato, alguns coordenadores evidenciaram a integração com os serviços de saúde apenas com convênios firmados entre os serviços públicos e os desenvolvidos nas clínicas das faculdades, não entrando no mérito da participação de docentes nos serviços, no seu planejamento e avaliação, e dos profissionais do serviço na docência. De modo semelhante, a mera atuação de docentes como profissionais dos ser- viços de saúde públicos, como apontada por alguns coordenadores, não é por si indicativa de uma efetiva integração da faculdade com os serviços públicos, ainda que potencialmente possa contribuir para tanto.

Os resultados relacionados à capacitação docente foram mais positivos, uma vez que a maioria das faculdades (nove) relatou estar comprometida de modo abrangente com a capacitação docente, sistematicamente promovida e tida como parte de sua política institucional. Com exceção de uma faculdade que relatou não oferecer ou raramente oferecer formação didáticopedagógica aos professores, as demais (cinco) também relataram que se preocupam com esta questão, promovendo periodicamente cursos de orientação docente.

Em relação a orientação didática e aos cenários de ensino-aprendizagem, observou-se que, embora a concepção e a solução de problemas em grupos pequenos, com ênfase na realidade de saúde e com abordagem multidisciplinar, valorizando a aprendizagem ativa e crítica dos estudantes e realizando práticas também em serviços de saúde públicos e espaços comunitários seja desejável e recomendada pelas DCN, parece ainda se tratar de uma realidade distante. Chama atenção a concentração de respostas (doze) na alternativa "b", que referia o uso de "metodologias alternativas que buscam a interatividade com os estudantes" - contudo, pouco evidenciadas pelos coordenadores e "com alguma integração multidisciplinar". Possivelmente a polarização das respostas se deveu a esta última parte da afirmativa, que foi referenciada algumas vezes nas justificativas e evidências. Ressalte-se, contudo, o conceito de multidisciplinaridade percebido, restrito à integração de disciplinas clínicas dentro do próprio curso de Odontologia.

Apenas dois cursos oferecem orientação tutorial permanente com avaliação interativa/ formativa, sendo que deles apenas um aportou evidência quanto à tutoria. A maioria (oito) relatou desenvolver os processos de ensino-aprendizagem e avaliativo de modo correspondente a um comprometimento pontual (centrado no professor em grandes e pequenos grupos, com a avaliação articulando teoria e capacidades práticas) e os demais (cinco), correspondente a um comprometimento inexpressivo (com o ensino baseado na transmissão de conteúdos e no treinamento de habilidades, e com a avaliação baseada em provas escritas e habilidades demonstradas).

A unidade temática "concepção de ética” buscava identificar, entre as diferentes formas que a 
ética pode assumir no currículo acadêmico, a predominante. Apenas uma instituição relatou abordá-la somente como Deontologia e quatro relataram compreender por ética, tanto o estudo dos deveres profissionais e princípios legais, quanto o estudo dos juízos morais aplicados à vida e às ações de saúde. Portanto, as respostas estiveram polarizadas na alternativa mais abrangente, cuja concepção de ética é a da "dimensão da FP, desenvolvida a partir da educação moral, do exercício político de cidadania, da capacidade de reflexão, de crítica e de autocrítica”. Porém, como já comentado em perfil do egresso e em conteúdos, tais competências não foram evidenciadas ao longo dos questionários devolvidos. Surge então um questionamento sobre a maioria dos coordenadores ter elegido esta afirmativa: não se deveria ao fato de esta concepção de ética lhes parecer melhor, mais completa, mais adequada? Reforça esta sugestão a presença de justificativas e evidências apontando tal concepção contida apenas em documentos acadêmicos. Porém, nem tudo que está no papel ocorre efetivamente, frequentemente sendo objetivos que ainda precisam ser perseguidos.

A unidade temática ética docente apresentou resultados ainda mais polarizados. O corpo docente de todos os cursos parece julgar que a educação moral faz parte da tarefa pedagógica, não atribuindo tal responsabilidade apenas às famílias e ao ensino fundamental. Mas apenas três coordenadores admitiram que, mesmo assim, a educação moral não está incluída na programação curricular. Isto poderia levantar um questionamento sobre a própria ética docente e uma atuação negligente dos professores face a uma de suas atribuições, ou ainda, a um entendimento de que a educação moral não precisa estar incluída no planejamento curricular, uma vez que o bom exemplo profissional poderia ser suficiente. Poder-se-ia pensar que nos demais cursos (doze) tal realidade fosse oposta, porém, na análise dos resultados, observou-se uma falha na formulação da afirmativa mais abrangente desta questão, onde constava "corpo docente que julga que a educação moral faz parte da tarefa pedagógica e atua considerando os valores que permeiam a educação e as relações humanas, conscientes de que representam um modelo profissional e que, portanto, influenciam os estudantes". A falha consistiu, pois, em não acrescentar que a educação moral faz parte da programação curricular, o que tornaria esta afirmativa oposta à alternativa anterior. Assim, não se pode considerar que na maioria dos cursos tal fato ocorra. De qual- quer forma, tais resultados são sugestivos de que os docentes consideram que o simples exemplo do bom profissional seja suficiente para dar conta da formação ética de seus estudantes, como se a formação moral decorresse naturalmente da formação técnica ${ }^{2}$.

Seria esperado que as doze faculdades que responderam a alternativa mais abrangente em relação à ética docente, repetissem sua escolha quanto à inserção ética curricular. Isto porque seria coerente que, uma vez conscientes e atuantes em relação à formação ética dos estudantes, buscassem imprimir à maioria dos conteúdos/ competências desenvolvidos, um caráter ético de forma transversal. No entanto, apenas nove cursos o fizeram. Os demais (seis) relataram que o corpo docente predominantemente está preocupado com o ensino técnico-científico, embora alguns professores se preocupem em abordar as implicações éticas da prática odontológica para além das questões legais, o que corroboraria a possível concepção citada acima: ser “bom” profissionalmente, tecnicamente falando, bastaria para ser bom exemplo moral. Esta questão foi a segunda de todas com o menor número de justificativas e/ou evidências aportadas pelos coordenadores. Mas a ausência de informações pode ser em si uma informação, especialmente se analisada em seu contexto, no qual as duas unidades temáticas anteriores também tiveram poucas justificativas e evidências apresentadas. Poderia ser a temática da ética considerada mais difícil pelos coordenadores de ser evidenciada ou exemplificada? E assim sendo, a que isto se deveria? Talvez a uma menor tangebilidade do tema, ou a um menor conhecimento/experiência, ou a uma menor valorização?

Aparentemente, a unidade disciplinas éticas foi a que os coordenadores apresentaram mais dificuldades para eleger uma alternativa. Atribuise a isto o fato da questão buscar identificar a existência de disciplinas relacionadas à ética, ou seja, de tratar de uma questão bastante concreta com apenas três respostas possíveis e pré-definidas. Evidentemente, a realidade é sempre mais múltipla e imprevisível do que um simples questionário possa contemplar. Mas pensando nisso as afirmativas foram elaboradas com algum grau de generalização, ademais de oferecer um espaço aberto para as devidas explicações. Porém, observou-se em outros nove questionários, ausência de informações extras e mais específicas sobre as disciplinas éticas efetivamente oferecidas nos cursos. Dos quatro questionários com inconsistências verificadas nesta questão, os três 
que assinalaram "c) além de oferecer uma disciplina de Bioética, aborda-a como tema curricular transversal em diferentes disciplinas e atividades" parecem ter valorizado a transversalidade apontada e desconsiderado a existência de uma disciplina específica de Bioética como parte constitutiva e fundamental da resposta. Contudo, a presença da temática ética de forma transversal no currículo, considerada fundamental para a formação ética dos estudantes, era conteúdo da questão anterior, estando esta interessada na pesquisa por disciplinas específicas de Bioética e/ou conjuntas com Deontologia. Assim, o total de faculdades que apontou uma resposta de comprometimento abrangente deve ser considerado com cautela. Os resultados registrados como 4 abrangentes (c - disciplina de Bioética e transversalidade), 6 pontuais (b - disciplina conjunta ou específica de Bioética) e 5 inexpressivos (a - sem disciplina de Bioética), talvez fossem mais fidedignos se indicassem 1, 7 e 7 , respectivamente. Neste caso, representariam a presença de apenas uma faculdade com a disciplina curricular de Bioética, quase metade das faculdades com a temática da Bioética associada à Deontologia e/ou outros conteúdos, e a ausência da Bioética enquanto disciplina na outra "metade" das faculdades. Isto iria ao encontro dos resultados encontrados em uma pesquisa que identificou a existência de disciplinas exclusivas de Bioética no currículo de apenas 4 cursos $(8,8 \%)$ do total de 45 cursos de graduação em Odontologia no estado de São Paulo, em $2006^{22}$.

Os resultados também indicaram a presença de professores de Bioética com formação específica na área, constituindo equipes multidisciplinares, em apenas três faculdades. Os demais cursos (doze) estão divididos pela metade em relação ao fato de terem ou não docentes com formação específica em Odontologia Legal e/ou Bioética, de modo coerente aos dados já discutidos. Os docentes envolvidos com tais disciplinas, quando sem formação específica em nenhuma das áreas (Deontologia ou Bioética) são professores de "Odontologia Social", ou de "áreas afins", ou ainda professores, segundo os coordenadores, que apresentam "interesse mais destacado". Desta maneira e juntamente com o observado em disciplinas éticas, esta unidade temática demonstra uma pequena valorização da Bioética por parte das faculdades de Odontologia, como também concluíram Musse et al..$^{22}$, enquanto disciplina que tem muito a contribuir com a excelência da FP. Ao mesmo tempo, levanta novamente a questão da atribuição de maiores responsabilidades aos pro- fessores de Saúde Coletiva, como se tudo que não fosse matéria das ciências básicas ou clínicas, estivesse sob seu domínio de conhecimento e fosse de sua exclusiva responsabilidade. Por outro lado, há que se considerar as dificuldades impostas pelos aspectos administrativos das universidades (departamentalização, fragmentação disciplinar atrelada a estatutos departamentais, etc.), bem como o exercício de autoridades e de poder que lidam com monopólios e legitimidades, e que reconhecidamente fazem parte do cotidiano das instituições universitárias.

$\mathrm{Na}$ última unidade temática, oito faculdades elegeram a alternativa que aponta um comprometimento mais abrangente em relação à formação ética (abordagem da Bioética em sua pluralidade de referenciais teóricos e campos de reflexão), seis a alternativa de caráter pontual (aborda predominantemente o referencial bioético principialista) e apenas uma, a alternativa mais inexpressiva (predominantemente não aborda referenciais de Bioética). Apesar destes resultados aparentemente positivos, dez faculdades deixaram totalmente em branco o espaço reservado para isto, mais que em qualquer outra questão. Questiona-se, portanto, tais dados, inclusive porque a vivência da alternativa mais abrangente seria esperada naquelas faculdades que efetivamente dedicam uma disciplina específica à Bioética, com professores com formação específica. Como poderiam discutir tal temática em sua pluralidade de referenciais teóricos professores sem esta formação ou, ao menos, sem uma capacitação ampliada? Poderia o entendimento dos coordenadores sobre formação estar restrito apenas aos cursos formais? Diferentemente de outras questões que podem ter sido mais positivamente respondidas pela intangibilidade de seus temas, nesta as respostas eram bastante concretas, inclusive devendo ser parte de ementas de disciplinas. Assim, novamente a possibilidade da eleição da alternativa que parece a mais adequada vem à tona. Ou talvez tal inconsistência possa ser atribuída a um desconhecimento por parte dos respondentes acerca do tema?

Embora assegurados quanto ao anonimato durante todo o processo de pesquisa e após a publicação dos resultados, é possível conjeturar que o receio de alguma forma de identificação com repercussões negativas possa ter contribuído também com a forma de valorar e responder à pesquisa de um modo possivelmente superestimado. A este respeito, Lampert ${ }^{14}$ relata "a forma 'receosa' como os colegiados explicitam as características desfavoráveis, ante as conhecidas 
recomendações em educação médica. "É como se houvesse, implícita, a perspectiva de uma possível ação punitiva, por algum dever não cumprido". Suposições como estas tentam ser respostas possíveis, ainda que sempre tragam consigo mais perguntas, entre elas: não deveria haver um equilíbrio de respostas entre as categorias temáticas "abordagem pedagógica" e "abordagem ética"?

Na Tabela 2, visualizam-se as áreas expandidas nos modelos radiados de cada curso e em cada categoria temática. Pode-se observar que apenas 2 faculdades ( 1 e 7 ) apresentaram resultados equilibrados entre as categorias possíveis de comparação por abarcarem uma mesma quantidade de área nos modelos radiados. Todas as demais apresentaram um desequilíbrio, sendo em oito delas o desequilíbrio para o lado da abordagem ética (área de expansão maior). O mesmo fica evidenciado na média de todas as faculdades, com uma pequena diferença de percentual de área expandida maior na categoria abordagem ética $(33,64 \%)$ que em abordagem pedagógica $(31,90 \%)$.

Inconsistências foram percebidas em 20 questões $(9,25 \%)$ quando da análise das alternativas eleitas frente às justificativas e evidências apontadas. Cabe considerar que se mais justificativas e evidências houvessem sido informadas este número possivelmente seria ainda maior. Quando, num exercício de curiosidade, tais inconsistências foram consideradas verdadeiras, portanto modificando as alternativas de respostas, observou-se uma alteração importante nos resultados das categorias temáticas. Assim, por exemplo, a categoria abordagem pedagógica que apresenta 46 respostas abrangentes, 31 pontuais e 13 inexpressivas (Tabela 1), passaria a ter 38,36 e 16 , respectivamente, números bastantes mais equilibrados, especialmente os dois primeiros, passíveis de comparação entre si. De modo semelhante, mas ainda mais importante, ocorreu com os resultados totais: das 87 respostas abrangentes, ficariam 74, das 99 pontuais, permaneceriam 98, e as 25 inexpressivas aumentariam para 37. Ou seja, continuaria havendo um predomínio significativo de respostas relacionadas a um comprometimento pontual, mas haveria um deslocamento de respostas de comprometimento abrangente para as relacionadas a um comprometimento inexpressivo. Há que se considerar que tais resultados não poderiam ser tomados como válidos metodologicamente, pois são baseados em indícios apontados nos questionários e nas contradições observadas. Contudo, podem ser úteis na ponderação dos resultados simplesmente apontados pelos coordenadores, quando contextualizados.

Talvez as considerações tecidas até aqui possam justificar os desequilíbrios verificados entre as categorias temáticas, já que algum equilíbrio era esperado por tratarem todas de um mesmo processo, sendo complementares. De qualquer

Tabela 2. Comprometimento de cada uma das faculdades quanto à dimensão ética da formação profissional, em ordem decrescente, segundo o total de área expandida no modelo radiado e o número de inconsistências observadas nas respostas ao questionário.

\begin{tabular}{|c|c|c|c|c|}
\hline Faculdades & $\begin{array}{c}\text { Enfoque teórico } \\
(14,28 \%)\end{array}$ & $\begin{array}{c}\text { Abordagem pedagógica } \\
(42,85 \%)\end{array}$ & $\begin{array}{l}\text { Abordagem ética } \\
(42,85 \%)\end{array}$ & $\begin{array}{c}\text { Total } \\
(100 \%)\end{array}$ \\
\hline Faculdade 1 & $9,52 \%$ & $33,33 \%$ & $33,33 \%$ & $76,18 \%$ \\
\hline Faculdade 2 & $11,90 \%$ & $30,95 \%$ & $23,80 \%$ & $66,65 \%$ \\
\hline Faculdade 3 & $9,52 \%$ & $30,95 \%$ & $40,47 \%$ & $80,94 \%$ \\
\hline Faculdade 4 & $14,28 \%$ & $38,09 \%$ & $40,47 \%$ & $92,84 \%$ \\
\hline Faculdade 5 & $11,90 \%$ & $30,95 \%$ & $26,19 \%$ & $69,04 \%$ \\
\hline Faculdade 6 & $11,90 \%$ & $30,95 \%$ & $35,71 \%$ & $78,56 \%$ \\
\hline Faculdade 7 & $7,14 \%$ & $38,09 \%$ & $38,09 \%$ & $83,32 \%$ \\
\hline Faculdade 8 & $7,14 \%$ & $21,42 \%$ & $28,57 \%$ & $57,13 \%$ \\
\hline Faculdade 9 & $9,52 \%$ & $33,33 \%$ & $35,71 \%$ & $78,56 \%$ \\
\hline Faculdade 10 & $11,90 \%$ & $26,19 \%$ & $40,47 \%$ & $78,56 \%$ \\
\hline Faculdade 11 & $9,52 \%$ & $33,33 \%$ & $38,09 \%$ & $80,94 \%$ \\
\hline Faculdade 12 & $9,52 \%$ & $35,71 \%$ & $33,33 \%$ & $78,56 \%$ \\
\hline Faculdade 13 & $14,28 \%$ & $35,71 \%$ & $33,33 \%$ & $83,32 \%$ \\
\hline Faculdade 14 & $14,28 \%$ & $30,95 \%$ & $33,33 \%$ & $78,56 \%$ \\
\hline Faculdade 15 & $11,90 \%$ & $28,57 \%$ & $23,80 \%$ & $64,27 \%$ \\
\hline Média & $10,94 \%$ & $31,90 \%$ & $33,64 \%$ & $76,49 \%$ \\
\hline
\end{tabular}


forma, recomenda-se a análise sempre contextualizada dos dados apresentados. Com o mesmo cuidado deve ser considerado o valor médio total das áreas expandidas de 76,49\% (Tabela 2), que classifica as faculdades participantes de um modo geral como de comprometimento pontual com tendência a abrangente com a dimensão ética da formação de seus estudantes.

$\mathrm{Na}$ Tabela 3, as faculdades estão classificadas em ordem decrescente segundo a área expandida de seus modelos radiados. Deste modo, três cursos foram caracterizados como comprometimento abrangente, nove como comprometimento pontual com tendência a abrangente e 3 como comprometimento pontual com tendência a inexpressivo.

Esta classificação ratifica os resultados anteriormente apresentados de que a maioria das faculdades encontra-se numa situação intermediária em relação ao desenvolvimento da formação ética de seus estudantes, expressas em ações pontuais, localizadas. Ademais, permite identificar que nenhuma das faculdades foi classificada como de comprometimento inexpressivo, sendo pequeno o número de faculdades com comprometimento pontual com tendência a inexpressivo. Contudo, cabe lembrar que esta classificação deve ser analisada dentro do contexto de contra-

Tabela 3. Comprometimento de cada uma das faculdades quanto à dimensão ética da formação profissional, em ordem decrescente, segundo o total de área expandida no modelo radiado e o número de inconsistências observadas nas respostas ao questionário.

\begin{tabular}{lcc}
\hline Faculdades & $\begin{array}{c}\text { Área } \\
\text { expandida }\end{array}$ & Comprometimento \\
\hline Faculdade 4 & $92,84 \%$ & Abrangente \\
Faculdade 13 & $83,32 \%$ & Abrangente \\
Faculdade 7 & $83,32 \%$ & Abrangente \\
Faculdade 3 & $80,94 \%$ & Pontual A \\
Faculdade 11 & $80,94 \%$ & Pontual A \\
Faculdade 12 & $78,56 \%$ & Pontual A \\
Faculdade 6 & $78,56 \%$ & Pontual A \\
Faculdade 14 & $78,56 \%$ & Pontual A \\
Faculdade 9 & $78,56 \%$ & Pontual A \\
Faculdade 10 & $78,56 \%$ & Pontual A \\
Faculdade 1 & $76,18 \%$ & Pontual A \\
Faculdade 5 & $69,04 \%$ & Pontual A \\
Faculdade 2 & $66,65 \%$ & Pontual I \\
Faculdade 15 & $64,27 \%$ & Pontual I \\
Faculdade 8 & $57,13 \%$ & Pontual I \\
\hline
\end{tabular}

dições e inconsistências verificadas na análise do instrumento, permitindo imaginar uma possível mobilidade entre elas, na dependência de alguns fatores, entre eles, do nível de crítica realizado por cada coordenador.

\section{Conclusões}

Podem-se elencar os fatores presentes no processo educativo como mais ou menos avançados no sentido de contribuir com um compromisso maior ou menor, mais ou menos abrangente das faculdades com a dimensão ética da FP. Evidentemente, generalizações como estas têm apenas a função de indicar um panorama atual, pois a realidade é diversa e dinâmica. Como se pôde perceber na apresentação dos dados por parte dos cursos, os matizes de cada um revelam a complexidade do tema e o atual contexto de mudanças curriculares indica a transitoriedade das situações reveladas.

Ressalva-se, cabe dizer, que os principais avanços foram observados em relação à capacitação docente, pela valorização da formação/aperfeiçoamento didático-pedagógico dos professores, em relação ao perfil do egresso, pela preocupação com a formação de profissionais capacitados a atuar nos serviços públicos, e em relação à estrutura curricular, pelos avanços no sentido da integração do currículo acadêmico e do desenvolvimento de conteúdos profissionalizantes precocemente.

Por outro lado, os atrasos mais evidentes foram identificados em relação a conteúdos, pela pouca valorização da formação humanística, cultural e política, em relação à orientação didática e a cenários de ensino-aprendizagem, e a tutoria e avaliação, por conta dos pressupostos e métodos ainda bastante tradicionais do processo educativo, bem como em relação a disciplinas éticas e formação docente, pela incipiente presença da Bioética enquanto disciplina e tema transversal curricular, e pela escassa formação específica de seus docentes.

Outros fatores ou unidades temáticas, embora com indícios de avanços em relação a uma situação mais tradicional, ainda constituem fragilidades no processo educativo, como por exemplo, o enfoque teórico e a integração com serviços públicos. Há ainda outras unidades temáticas - concepção de ética, ética docente, inserção ética curricular e referenciais teóricos em Bioética - sobre as quais seria imprudente elaborar um julgamento com base apenas nos dados até então obtidos, uma vez que estes sugerem muitos 
questionamentos, indicando a necessidade de serem mais investigados.

Sinalizar os pontos fortes e fracos da formação ética em Odontologia pode contribuir para uma revisão de tal processo, em cada instituição, de acordo com suas peculiaridades, de modo a reforçar insuficiências e a desenvolver potencialidades percebidas, mesmo naquelas cujo comprometimento com a formação ética já possa ser considerado abrangente. Neste sentido, o instrumento formulado neste trabalho ${ }^{21}$ poderia ser empregado pelos próprios cursos para se auto avaliarem, permitindo um redirecionamento de suas ações.
O predomínio de respostas relacionadas a um comprometimento pontual e à classificação da média como de comprometimento pontual com tendência a abrangente significam que tais instituições apresentam um compromisso com esta dimensão da formação provavelmente não tão pequeno quanto tradicionalmente, mas também não tão abrangente quanto poderá ser, caso sigam efetivamente as DCN. Não que as Diretrizes contemplem explicitamente o tema, mas ao reorientar o processo de formação em busca de um novo perfil profissional, socialmente mais relevante, estariam contribuindo em parte para a formação de profissionais também eticamente mais competentes.

\section{Colaboradores}

M Finkler idealizou a pesquisa, coletou e analisou os dados e redigiu o trabalho. JC Caetano e FRS Ramos orientaram a pesquisa e aprovaram a redação final do artigo.

\section{Agradecimentos}

A CAPES pela bolsa de Estágio de Doutorando no Exterior 


\section{Referências}

1. Martínez MM, Estrada MRB, Bara FE. La universidad como espacio de aprendizaje ético. Rev IberoAmer Educ 2002; 29:14-43.

2. Rego S, Gomes AP, Siqueira-Batista R. Bioética e humanização como temas transversais na formação médica. RBEM 2008; 32(4):482-491.

3. Finkler M, Campognara S, Reibnitz KS, Backe V, Caetano JC. Metodologias ativas no processo ensino-aprendizagem: possibilidade para uma prática educativa mais participativa na área da saúde. $A B E-$ NO 2008; 8(2):140-145.

4. Arouca R, Rego S, Machado MH. O papel da escola na educação moral de estudantes de Odontologia. Rev Bras Odontol 2008; 65(2):211-215.

5. Cristino PS. Clínicas integradas antecipadas: limites e possibilidades. ABENO 2005; 5(1):12-18.

6. Peret ACA, Lima MLR. A pesquisa nos critérios de avaliação da CAPES e a formação do professor de Odontologia numa dimensão crítica. ABENO 2005; 5(1):46-51.

7. Finkler M, Calvo MC, Caetano JC, Ramos, FRS. Um novo olhar bioético sobre as pesquisas odontológicas brasileiras. Cien Saude Colet 2009; 14(4):12051214. Disponível em: http://www.abrasco.org.br/ cienciaesaudecoletiva/artigos/artigo_int.php?id_ artigo $=398$

8. Gonçalves ER. $O$ atendimento a pacientes na clínica odontológica de ensino: a percepção docente sob o olhar da Bioética [dissertação]. Florianópolis (SC): Universidade Federal de Santa Catarina; 2005.

9. Rego S. A Formação Ética dos Médicos: saindo da adolescência com a vida (dos outros) nas mãos. Rio de Janeiro: Fiocruz; 2003.

10. Dubar C. A socialização: construção das identidades sociais e profissionais. São Paulo: Martins Fontes; 2005.

11. Cortina A. O fazer ético: guia para a educação moral. São Paulo: Moderna; 2003.

12. Gracia D. Fundamentación y enseñanza de la Bioética. Santafé de Bogotá: El Buho; 2000.

13. Machado MH. Sociologia das profissões: uma contribuição ao debate teórico. In: Machado $\mathrm{MH}$, organizador. Profissões de saúde: uma abordagem sociológica. Rio de Janeiro: Fiocruz; 1995. p.13-33.

14. Lampert J. Tendências de mudanças na formação médica no Brasil. São Paulo: Hucitec; 2002.
15. Feuerwerker L. Além do discurso de mudança na educação médica: processos e resultados. São Paulo: Hucitec; 2002.

16. Berger PL, Luckmann T. A construção social da realidade: tratado de sociologia do conhecimento. Petrópolis: Vozes; 1985.

17. Hughes EC. E.C. The making of a physician: general statement of ideais and problems. In: Mackay L, Soothill K, Melia KM, organizadores. Classic texts in health care. Oxford: Butterworth-Heinemann; 1998. p. 136-39.

18. Apple MW. O currículo oculto e a natureza do conflito. In: Apple MW, organizador. Ideologia e currículo. São Paulo: Brasiliense; 1982. p. 125-157.

19. Minayo MCS, Souza ER, Constantino P, Santos NC. Métodos, técnicas e relações em triangulação. In: Minayo MCS, Assis SG, Souza ER, organizadores. Avaliação por triangulação de métodos. Rio de Janeiro: Fiocruz; 2005. Cap. 2.

20. Turato ER. Tratado de metodologia da pesquisa clínico-qualitativa: construção teórico epistemológica, discussão comparada e aplicação nas áreas da saúde e humanas. Petrópolis: Vozes; 2003.

21. Finkler M. Formação ética em Odontologia: realidades e desafios [tese]. Florianópolis (SC): Universidade Federal de Santa Catarina; 2009.

22. Musse JO, Boing AF, Martino FS, Silva, RH, Vaccarezza GF, Ramos DLP. O ensino da bioética nos cursos de graduação em Odontologia do estado de São Paulo. Arq. Ciênc. Saúde 2007; 14(1):13-16.

Artigo apresentado em 21/08/2009

Aprovado em 23/09/2009

Versão final apresentada em 05/10/2009 